\title{
Impact of the COVID-19 Pandemic on Career Intention Among Undergraduate Medical Students: A Single-center Cross-Sectional Study in Hubei Province
}

\section{Xue-lin Wang}

Xiangyang No.1 people's Hospital Affiliated to Hubei University of Medicine

Ming-xiu Liu

School of Nursing, Hubei University of Medicine

\section{Shuai Peng}

Hubei University of Medicine

\section{Lei Yang}

School of Nursing, Hubei University of Medicine

Chen Lu

Hubei University of Medicine

\section{Shi-cong Shou}

Hubei University of Medicine

Jian-ru Wang

Hubei University of Medicine

Jun-yi Sun

Hubei University of Medicine

Jia-qi Wang

Hubei University of Medicine

\section{Yan $\mathrm{Hu}$}

Hubei University of Medicine

Jun Zhao

School of Public Health, Hubei University of Medicine

Peng Duan ( $\nabla$ meduanpeng@163.com )

Xiangyang No.1 people's Hospital Affiliated to Hubei University of Medicine

\section{Research Article}

Keywords: Medical education, undergraduate students, career intention, COVID-19, cross-sectional study

Posted Date: July 14th, 2021 
DOI: https://doi.org/10.21203/rs.3.rs-622888/v1

License: (c) (1) This work is licensed under a Creative Commons Attribution 4.0 International License. Read Full License 
Article Type: original Article

\section{Impact of the COVID-19 pandemic on career intention among undergraduate medical students: A Single-center Cross-Sectional Study}

\section{in Hubei Province}

Xue-lin Wang, ${ }^{\mathrm{a}, \#}$, Ming-xiu Liu ${ }^{\mathrm{b}, \#}$, Shuai Peng ${ }^{\mathrm{c}}$, Lei Yang ${ }^{\mathrm{b}}$, Chen Lu ${ }^{\mathrm{d}}$, Shi-cong Shou ${ }^{\mathrm{d}}$, Jian-ru Wang ${ }^{\mathrm{d}}$, Jun-yi Sun ${ }^{\mathrm{d}}$, Jia-qi Wang ${ }^{\mathrm{d}}$, Yan Hu ${ }^{\mathrm{d}}$, Jun Zhao $^{\mathrm{d}, *}$, Peng Duan ${ }^{\mathrm{a},{ }^{*}}$.

\section{Abstract}

Background: Undergraduate medical (UM) students faced the realities of the difficulties inherent in medical careers due to the coronavirus 2019 (COVID-19) outbreak. Thus imperative containment measures could affect UM students' career intentions. There is limited information regarding the factors potentially associated with these students' career change intentions.

Methods: we conducted a cross-sectional survey to investigate the impact of the COVID-19 pandemic on career intention and the associated factors in UM students in August 2020. Univariate analyses and logistic regression analysis were used to identify the factors that contributed to any change of career intention. 
Results: A total of 2,040 medical students were contained from Hubei University of Medicine. The change of career intention was related to grade, attitude towards being a health worker and the impact of the COVID-19 pandemic.

Conclusions: Changes in career intentions were particularly influenced by grade, attitude towards being a health worker, and the degree of COVID-19's impact on the participants' lives. Treating large-scale public health emergencies in rational way, setting up correct views of occupation choice and building reasonable career planning may reduce the loss of medical talents.

Keywords: Medical education, undergraduate students, career intention, COVID-19, cross-sectional study.

\section{Introduction}

The intention or desire to engage in a certain career comes from an inner motivation for personal career choice. ${ }^{1}$ Having a personal career choice boosts an individuals' passion for work and leads them to achieve greater achievements in their careers. ${ }^{2}$ Therefore, Undergraduate Medical (UM) students' longing for and identification with the profession of doctor and their willingness to be healthcare practitioners will have an impact on their future career choice and medical practice. This identification may, in turn, affect the number of doctors in society and their degree of professionalism. A retrospective study showed that from the beginning of 2005 to the end of 2014, China produced 4,314,791 five-year clinical medical graduates and 413,186 five-plus-two programme medical graduates: a total of 4,727,977 clinical medical graduates. However, 
during this period, there was an increase of only $752,233(15.91 \%)$ in the total number of registered clinical physicians in practice. ${ }^{3}$ This study confirms the high attrition rate among medical graduates and physicians in China over the past 10 years. In China, the doctor-patient relationship still does not engender optimism. ${ }^{4}$ It is possible that certain factors influence whether UM students choose to continue their pursuit of a medical profession, including their cognition, doctor-patient conflicts, perceptions of the medical practice environment, salary level, and expectations regarding doctor-patient relationships..$^{4,5}$

At the end of 2019, the outbreak of a novel coronavirus pneumonia, which was named COVID-19, aroused global attention. The World Health Organization (WHO) characterized the COVID-19 outbreak as a pandemic. ${ }^{6}$ The global pandemic continues to spread in 2021 , the data reported by Worldometers ${ }^{7}$ showing that the global accumulated definite case reached more than 160 million and the death toll reached more than 3 million by May 13, 2021. As a result, people worldwide have been under enormous pressure and have experienced severe psychological distress. ${ }^{8,9}$ A series of studies on the effects of COVID-19 on physical health have been endlessly emerging. The significance of disastrous events on a community can be helpful in evaluating citizens' value systems. After the Wenchuan Earthquake in China, in the disaster-stricken areas, social values dominated university students' expressions about their value systems. ${ }^{10}$ So, the continued impact of the epidemic had a knock-on effect on every aspect of college students' lives ${ }^{11,12}$, especially the psychological impact on their professional value intentions and views of their 
life choices. ${ }^{12,13}$

We hypothesized in this study that COVID-19 may have influenced medical students' intentions to practice medicine. For this purpose, a cross-sectional online survey was conducted among UM students from Hubei University of Medicine during the epidemic of COVID-19. This study aimed to examine the COVID-19 epidemic's influence on UM students' career intentions and the factors influencing these intentions.

\section{Methods}

\section{Study Design and Study Population}

This study is a cross-sectional study. All the information was gathered through an online questionnaire. The questionnaire was developed, reviewed, and pre-tested by Dr Peng Duan and his colleagues. Each participant was informed and agreed to the sample collection once they finished and submitted the questionnaire. For the methods, we adopted an anonymous self-administered questionnaire, and students of Hubei University of Medicine were surveyed to investigate the impact of the COVID-19 pandemic on their career intentions.

The questionnaire was distributed through the Chinese professional survey website Wenjuanxing (http://www.wjx.com, Changsha Ranxing Information Technology Co., LTD, Changsha, China). The online questionnaires were distributed from August 14 to August 28, 2020, through the widely used WeChat platform for UM students from Hubei University of Medicine. The participants were identified by their network IP. The 
study protocol was approved by the Ethics Committee Board at Hubei University of Medicine (No.2020-TH-062).

\section{Variables and measurement}

The online survey consisted of three main sections: (1) social demographic information; (2) degree of concern about the COVID-19 pandemic; and (3) whether the career intention changed during the COVID-19 pandemic. Social-demographic characteristics included age, gender, parents' educational level, place of residence, monthly household income, monthly personal expenses, grade, specialty, relatives' medical background, and parents' attitude toward medical study. The degree of concern about COVID-19 was estimated through the time spent focusing on the pandemic, subjective feelings, and their impact on daily life. The change of career intention sub-section included career choice, career preference, career perspective, and ideal workplace.

\section{Data collection and quality control}

The questionnaire was administered over a two-week period. Firstly, the research group contacted the UM students in each class. The researchers explained the study procedures and then sent their students a link to the electronic questionnaire via WeChat. Each participant completed the survey anonymously. An Excel file was generated after the whole class submitted the survey. Upon analysis, we combined all Excel files and saved them as an Excel workbook file. 
To avoid repetition, participants who filled out questionnaires with the same IP address $(n=27)$ were excluded from further analysis. Questionnaires indicating the respondents' ages were more than 30 or less than 17 were regarded as invalid ( $\mathrm{n}=7)$. Among the samples, four postgraduate students were also excluded. After these exclusions, a total of 2,040 participants were ultimately included in the analysis, yielding an effective response rate of $98.4 \%$.

\section{Data analysis}

Data analysis was performed by using R software version 4.0.2 (R Core Team (2020). R: A language and environment for statistical computing. R Foundation for Statistical Computing, Vienna, Austria. URL https://www.R-project.org/). Descriptive statistics were used to represent the demographics and concern about COVID-19 among study participants. Combining all of the variables, we made some adjustments

to make the survey more suitable. Parents' educational level was divided into four groups: middle school and below, high school, college, and university and above. The subjects were asked to rate the overall effect of the COVID-19 pandemic on their life. Items included learning environment, sleep quality, diet, travel ability, happiness, life routine, and psychology. Items selected were then summed for a total score. We then evaluated the degree of the pandemic's impact on each UM student with higher scores indicating greater impacts. 
Continuous variables were reported as a mean, and standard deviation and categorical data were proportions. The difference between the categorical variables was assessed by using the chi square, while students' $t$-tests were used to evaluate the variance in continuous variables. The significance level was set at 0.05 , and two-tailed $p$-values were reported.

A logistic regression analysis was performed by using multiple covariates as independent variables and whether the career intention changed during the COVID-19 pandemic as outcome variables. Multiple covariates and potential confounders were controlled to measure the association of change of career intention during the COVID-19. These covariates included age, sex, residency, parents' educational level, monthly family income, monthly personal expenses, grade, major, time spent concerned about COVID-19, viewing healthcare work as dangerous, having relatives with a medical background, parents' attitude towards medical schools, and the degree of COVID-19's impact. Odds ratios and $95 \%$ confidence intervals were reported. A stratified analysis was conducted by categorizing the respondents according to specialty (clinical medicine, nursing). The association between specialty and the change of career intention was displayed using a forest plot.

\section{Results}

\section{Demographics}

A total of 2,040 participants (Males=546, Females=1,494) completed the survey. The mean age of participants was $20.4 \pm 1.4$ years. Most 
participants $(1,386,67.9 \%)$ were Hubei residents, and 55.6\% were from rural areas. UM students were divided into three groups: clinical medicine $(803,39.4 \%)$, nursing $(989,48.5 \%)$, and others $(248,12.2 \%)$. The score of the impact degree of the pandemic was $3.5 \pm 1.6$. The study participants' complete demographic details are represented in Table 1.

\section{Univariate analysis}

After locking out missing values $(\mathrm{n}=97)$, most students $(1,796,92.4 \%)$ maintained their career choice, but $7.6 \%$ had changed their choice. The chi-square test revealed that grade $(P=0.008)$ and regarding healthcare work as dangerous $(P=0.019)$ were correlated with changing the career choice during the COVID-19 pandemic. Grade $2(61,41.5 \%)$ and Grade $3(30,20.4 \%)$ had the largest number of UM students who changed the career choice, and 66\% viewed healthcare work as dangerous. The degree of COVID-19's impact presented a significant association $(P=0.006)$ with career choice. Those who indicated they may change their career choice had higher mean scores in the category of degree of impact, as compared to those who maintained their career choice. Additional details on univariate characteristics are presented in Table 1.

\section{Multiple logistic regression analysis}

The variables that were observed to be significantly associated with change of career choice during the COVID-19 pandemic were Grade 2 ( $P=0.023)$, Grade $5(P=0.048)$, attitude towards medical career $(P=0.039)$, and having relatives with a medical background $(P=0.047)$. Compared 
with those in Grade 1, those who were in Grade 2 (adjusted odds ratio [aOR] 1.89, [95\%CI, 1.09-3.26]) and grade 5 (aOR, 2.43 [95\%CI, 1.01-5.86]) were more likely to change their career choice. Those who viewed healthcare as dangerous were more likely to change the career choice for the aOR 1.49 (95\% CI [1.02-2.32]). Those who had relatives with a medical background were more likely to change the career choice (aOR,1.53 [95\%CI, 1.01-2.32]). Additional details on logistic regression characteristics on career choice are presented in Table 2.

The degree of COVID-19's impact was a common factor that was significantly associated with career preference (aOR, 1.17 [95\%CI, 1.06-1.30]), career perspective (aOR, 1.08 [95\%CI, 1.01-1.15]), and ideal workplace (aOR, 1.11 [95\%CI, 1.02-1.21]). Factors associated with change of career preference were Grade 2 (aOR, 2.21; [95\%CI, 1.29-3.78]), personal expenses being between 500¥ to 999¥ per month (aOR, 0.39; [95\%CI, 0.18-0.84]) and parents' attitude towards their child being a UM student (aOR, 1.64 [95\%CI, 1.13-2.38]). Compared to those with monthly expenses of less than $500 ¥$, those whose expenses were $500 ¥$ to $999 ¥$ were less likely to change their career preferences (aOR, 0.39 [95\% CI, 0.18-0.84]); however, no significant difference was observed in those whose expense were in other levels. Compared to those who had their parents' support in attending medical schools, those who had parents who neither supported nor were against were more likely to change the career preference (aOR, 1.64 [95\%CI, 1.13-2.38]). Participants' hometown $(P=0.018)$ and whether they had relatives with a medical background $(P=0.021)$ were associated with the change of career perspective. Compared to those whose were from rural areas in Hubei, those 
whose hometowns were in urban areas were more likely not to change their career perspective whether they were from Hubei (aOR, 0.69 [95\%CI, 0.52-0.92]) or not (aOR, 0.60 [95\%CI, 0.41-0.89]). Participants who had relatives with a medical background (aOR, 1.37 [95\%CI, 1.05-1.78]) were more likely to change their career preference. Age $(P=0.018)$ and major $(P<0.001)$ were associated with the change of ideal workplace. Higher ages were associated with higher possibilities of changing the ideal workplace (aOR, 1.17 [95\%CI, 1.03-1.34]). Nursing UM students were more likely to change the ideal workplace than were clinical UM students (aOR, 2.07 [95\%CI, 1.42-3.03]). Additional details on logistic regression characteristics on career preference, career perspective, and ideal workplace are presented in Table 3.

\section{Stratified analysis}

We performed a stratified analysis by UM students' major based on changing of career choice. Multiple logistic regression analyses identified that clinical UM students who were in Grades 4 and 5 were more likely to change the career choice (aOR 4.53 [95\%CI 1.31-15.65]) (figure1), and seeing healthcare work as dangerous was associated with nursing UM students' changing their career choice (aOR 1.73 [95\%CI 1.011-2.97], figure 1). The detailed results of stratified analysis are shown in Figure 1.

\section{Discussion}

Our results are consistent with our hypothesis that the COVID-19 pandemic influenced UM students' career intentions. As we know, health 
workers are always under heavy pressure and face a high workload. UM students have seen the fight with the pandemic, which caused much more pressure and a heavier workload, particularly considering the lack of mature healthcare workers. UM students eventually realized the urgent need of a medical frontline even knowing they would later face a heavy burden. Previous studies have shown that ordinary people, including healthcare workers, suffered from this large-scale infectious public health event and experienced enormous disruptions to daily life, under unprecedented pressure. ${ }^{14,15}$ Moreover, the COVID-19 pandemic reflected not only the high risk of occupational exposure but also the urgent need of trained health workers. ${ }^{16}$

However, role models gave the frontline a sense of professional belonging. A Japanese research study found that although the COVID-19 pandemic influenced the overall performance of the medical professions, all participants showed a sense of belonging in medical professions. ${ }^{17}$ Faced with challenges and opportunities, it was highly likely that some UM students would change their career intentions.

In this study, we found that UM students from Grades 2 and 5 were more likely to change their career choice during the pandemic than were those in Grade 1. Public health emergencies have a negative effect on students' mental health. ${ }^{18}$ Grade 5 students need to balance the assignment of an internship and the postgraduate entrance exam preparation. If they fail the examination, they must either join the Resident Physician Standardized Training in China for three years or find another job. With such a heavy burden, some are likely to change their 
willingness to be healthcare workers. Thus, these factors remind us that we should put the occupation planning course on the agenda at Grade 2 to guide the students toward building an appropriate career plan and development ideology.

With the virus variation that was found in Great Britain and the sporadic cases that were reappearing in China, it is hard to forecast when the global epidemic situation will be controlled. Biomedical experts have pointed out that scientists should stay prepared because the virus keeps changing and the epidemic situation becomes the new normal. ${ }^{19}$ One research study found that a public health event that disrupted medical education led to significant changes in specialty choices both before and after the event, and this change was evident over a ten-year study period. ${ }^{20}$ As this was a cross-sectional retrospective study, the causal relationships could not be determined. Thus, it is difficult to tell at this stage whether the career-related concerns revealed by our findings will manifest as actual changes in career intentions.

Few studies have investigated the COVID-19 pandemic's impact on medical students' career intentions. Notably, the medical education system is diverse in different countries. Personal career intentions are jointly affected by intrinsic value factors, such as interests and professional identity, and external value factors such as career stability, income, and welfare. ${ }^{13}$ The pandemic of COVID-19 exactly affects medical students' career perceptions. ${ }^{21}$ It is vital to strengthen public health education. The training of vocational risk education and preventing occupational exposure should be followed for medical students and frontline health workers. Administrators should also increase investment in public health 
and enhance primary protection by transmitting basic knowledge of public health.

\section{Strengths and limitations}

For this study, we recruited a large sample of participants by describing the survey to potential respondents in neutral terms and making it short and easy to complete. Although ours was a sample of self-selected respondents, we achieved a representative sample with respondents from all grades of UM students with diverse birthplaces, family economic positions, and parents' educational levels. We used rigorous post-stratification weighting to permit us to extrapolate students' career intentions from different specialties.

This study has several limitations. First, the cross-sectional study means the causality cannot be proven. Further study is needed to clarify any associations. Secondly, the fact that we only looked at a single centre may result in selection bias, thus we cannot generalize the findings to the whole Chinese population. Next, because the data was collected through an online questionnaire that was released via WeChat, respondents were people who decided to participate in the survey. Therefore, this survey may suffer from the problems of self-selection.

\section{Conclusion}

Changes in career intentions were particularly influenced by grade, attitude towards being a health worker, and the degree of COVID-19's impact on the participants' lives. Thus, educators could present some strategies to guide students to build proper views about employment, which 
is significant for guiding medical humanistic education in order to reduce medical brain drain and to cultivate excellent health workers. Future studies are needed to explore the association of the COVID-19 pandemic with medical students' career intentions and its long-term influences.

\section{Ethics approval and consent to participate}

The study protocol was approved by the Ethics Committee Board at Hubei University of Medicine (No.2020-TH-062). Verbal informed consent was obtained by all participants and approved by the ethics committee.

\section{Consent for publication}

Data collection was anonymous. No details of participants are presented. Therefore, no consent for publication is required. This was confirmed by the local ethics committee.

\section{Availability of data and materials}

The datasets of this article are available from the corresponding author on a reasonable request.

\section{Competing interests}

All authors declare that they have no competing interests.

\section{Funding}


This study was supported by grants 81901567 from the National Natural Science Foundation of China, grant 2018CFB112 from the Natural Science Foundation of Hubei Province, grant Q20202105 and grant 2020559 from the Natural Science Foundation of Hubei Provincial Department of Education, grant YJ2019009 and grant 2019013 from Teaching Research Program of Hubei University of Medicine, grant YC2021019 from the Innovative Research Program for Graduates of Hubei University of Medicine, and grant 19Y03 from the Scientific and Technological Project of Shiyan City of Hubei Province.

\section{Authors' contributions}

Drs Duan and Zhao had full access to all the data in the study and takes responsibility for the integrity of the data and the accuracy of the data analysis. Ms X.-L. Wang and M.-X. Liu contributed equally as co-first authors (\#). Concept and design: P. Duan, J. Zhao. Acquisition, analysis, or interpretation of data: M.-X. Liu, L. Yang, S. Peng, C. Lu, S.-C. Shou, J.-R. Wang, J.-Y. Sun, J.-Q. Wang, Y. Hu. Drafting of the manuscript: X.-L. Wang, M.-X. Liu. Critical revision of the manuscript for important intellectual content: All authors have read and approved the manuscript. Statistical analysis: J. Zhao, X.-L. Wang. Obtained funding: P. Duan. Administrative, technical, or material support: J. Zhao. Supervision: P. Duan. Corresponding author (*): Peng Duan, PhD, Department of Obstetrics and Gynaecology, Xiangyang No.1 People's

Hospital, Hubei University of Medicine, Xiangyang 441000, China (meduanpeng@163.com); Jun Zhao, School of Public Health, Hubei University of Medicine, Shiyan 42000, China (stzhao@163.com).

\section{Author Affiliations}

a Department of Obstetrics and Gynaecology, Xiangyang No.1 People's Hospital, Hubei University of Medicine, Xiangyang, China (X.-L. 
Wang, P. Duan); ${ }^{b}$ School of Nursing, Hubei University of Medicine, Shiyan, China (M.-X. Liu, L. Yang); ${ }^{c}$ School of Fourth Clinical, Hubei University of Medicine, XiangYang, China (S. Peng); d School of Public Health, Hubei University of Medicine, Shiyan, China (J. Zhao, C. Lu, S.-C. Shou, J.-R. Wang, J.-Y. Sun, J.-Q. Wang, Y. Hu).

\section{Acknowledgments}

The survey was approved by the Ethics Committee Board at Hubei University of Medicine, The authors would like to thank all of the participants for their willingness to participate in the study and the time that they devoted to the study. The funder had no role in the design and conduct of the study; collection, management, analysis, and interpretation of the data; preparation, review, or approval of the manuscript; and decision to submit the manuscript for publication. Thanks for the financial support from all department. Thanks for our epidemiologist, Dr. J. Zhao, for the main statistical analysis.

\section{References}

1. Ajzen I, Kruglanski AW. Reasoned action in the service of goal pursuit. Psychological review. Oct 2019;126(5):774-786. doi:10.1037/rev0000155

2. Li C, Liu L, Zheng W, Dang J, Liang Y. A clean self reduces bribery intent. International journal of psychology : Journal international de psychologie. Apr 2019;54(2):247-255. doi:10.1002/ijop.12452

3. Lien SS KR, Fan AP, et al. 10-year trends in the production and attrition of Chinese medical graduates: an analysis of nationwide data. 2016;

4. LI Haobo CZ. Enlightenment of "Properly Handling Contradictions among People" to Building Harmornious Relationship between Doctors and Patients. 
Chinese Journal of Social Medicine Feburary 2020;37(01):12-15. doi:10.3969/j.issn.1673-5625.2020.01.004

5. Yanan Zheng HL, Dixiu Liu. Current Situation and Relationship Between Aggressive Behavior and Dark Triad of Medical Students in a Medical University in Ganzhou City. Medicine and Society. 2020;33(10):89-93.

6. Coronavirus - Rwanda: WHO Director-General's opening remarks at the media briefing on COVID-19. M2 Presswire. 10 August 2020;

7. Coronvirus Update (Live): 161,080,616 Cases and 3,345,018 Deaths from COVID-19 Virus Pandemic - worldometers. worldometers. https://www.worldometers.info/coronavirus/. Updated May 13, 2021.

8. Huang I, Lim MA, Pranata R. Diabetes mellitus is associated with increased mortality and severity of disease in COVID-19 pneumonia - A systematic review, meta-analysis, and meta-regression. Diabetes Metab Syndr. 2020;14(4):395-403. doi:10.1016/j.dsx.2020.04.018

9. Moein ST, Hashemian SM, Mansourafshar B, Khorram-Tousi A, Tabarsi P, Doty RL. Smell dysfunction: a biomarker for COVID-19. Int Forum Allergy Rhinol. 2020;10(8):944-950. doi:10.1002/alr.22587

10. Yan Xu FW, Huiyue Jia. A Comparison of Values of undergraduates from Sichuan and Beijing after the 512 Earthquake. Psychological exploration 2008;28(04):46-50.

11. Wang C, Horby PW, Hayden FG, Gao GF. A novel coronavirus outbreak of global health concern [published correction appears in Lancet. 2020 Jan $29 ;:$ ]. 
Lancet. 2020;395(10223):470-473. doi:10.1016/S0140-6736(20)30185-9

12. Ettman CK, Abdalla SM, Cohen GH, Sampson L, Vivier PM, Galea S. Prevalence of Depression Symptoms in US Adults Before and During the COVID-19 Pandemic. JAMA Netw Open. 2020;3(9):e2019686. Published 2020 Sep 1. doi:10.1001/jamanetworkopen.2020.19686

13. Hines A UO. Getting Ready for a Post-Work Future. Foresight and STI Governance. 2019;13(1):19-30.

14. Shi L, Lu ZA, Que JY, et al. Prevalence of and Risk Factors Associated With Mental Health Symptoms Among the General Population in China During the Coronavirus Disease 2019 Pandemic. JAMA Netw Open. 2020;3(7):e2014053. Published 2020 Jul 1. doi:10.1001/jamanetworkopen.2020.14053

15. Abbas M, Dhane M, Beniey M, et al. Repercussions of the COVID-19 pandemic on the well-being and training of medical clerks: a pan-Canadian survey. BMC Med Educ. 2020;20(1):385. Published 2020 Oct 27. doi:10.1186/s12909-020-02293-0

16. Yang Fu, JM, Mei Yin, et al. Risk factors and countermeasures of occupational exposure of medical workers under new coronavirus epidemic situation. Chinese Medical Ethics. 17 Nov. 2020. https://kns.cnki.net/kcms/detail/61.1203.R.20201117.0923.002.html.

17. Santos LMD. The Relationship between the COVID-19 Pandemic and Nursing Students' Sense of Belonging: The Experiences and Nursing Education Management of Pre-Service Nursing Professionals. Int J Environ Res Public Health. 2020;17(16):5848. Published 2020 Aug 12. doi:10.3390/ijerph17165848

18. Wathelet M, Duhem S, Vaiva G, et al. Factors Associated With Mental Health Disorders Among University Students in France Confined During the 
COVID-19 Pandemic. JAMA Netw Open. 2020;3(10):e2025591. Published 2020 Oct 1. doi:10.1001/jamanetworkopen.2020.25591

19. May M. 2021: research and medical trends in a post-pandemic world. Nat Med. 2020;26(12):1808-1809. doi:10.1038/s41591-020-01146-Z

20. Townsend MH. The effect of hurricane Katrina on medical student career choice. Acad Psychiatry. 2012;36(3):258-259. doi:10.1176/appi.ap.11030056

21. Byrnes YM, Civantos AM, Go BC, McWilliams TL, Rajasekaran K. Effect of the COVID-19 pandemic on medical student career perceptions: a national survey study. Med Educ Online. 2020;25(1):1798088. doi:10.1080/10872981.2020.1798088

Table 1 Socio-demographic characteristics of medical students and univariate analysis about whether change the career choice during COVID-19 pandemic $(n=2,040)$.

\begin{tabular}{|c|c|c|c|c|c|}
\hline & \multirow{2}{*}{ Variable } & \multirow{2}{*}{ Total $(n=2040)$} & \multicolumn{2}{|c|}{ Change of career choice during COVID-19a } & \multirow{2}{*}{$P$ value } \\
\hline & & & No $(n=1796)$ & Yes $(n=147)$ & \\
\hline \multicolumn{5}{|l|}{ Age (year) } & \multirow{2}{*}{0.112} \\
\hline mean $(\mathrm{SD})$ & & $20.4(1.4)$ & $20.4(1.4)$ & $20.6(1.4)$ & \\
\hline
\end{tabular}




\begin{tabular}{|c|c|c|c|c|}
\hline \multicolumn{5}{|l|}{ Sex } \\
\hline Male & $546(26.8)$ & $478(26.6)$ & $44(29.9)$ & \multirow[t]{2}{*}{0.438} \\
\hline Female & $1494(73.2)$ & $1318(73.4)$ & $103(70.1)$ & \\
\hline \multicolumn{5}{|l|}{ Residency } \\
\hline Hubei rural & $763(37.4)$ & $667(37.1)$ & $61(41.5)$ & \multirow{4}{*}{0.375} \\
\hline Hubei urban & $623(30.5)$ & $540(30.1)$ & $45(30.6)$ & \\
\hline Rural other than Hubei & $371(18.2)$ & $328(18.3)$ & $27(18.4)$ & \\
\hline Urban other than Hubei & $283(13.9)$ & $261(14.5)$ & $14(9.5)$ & \\
\hline \multicolumn{5}{|l|}{ Educational level of parents } \\
\hline Middle school or below & $958(47.0)$ & $848(47.2)$ & $68(46.3)$ & \multirow{4}{*}{0.939} \\
\hline High school & $577(28.3)$ & $501(27.9)$ & $43(29.3)$ & \\
\hline College & $190(9.3)$ & $169(9.4)$ & $12(8.2)$ & \\
\hline University or above & $315(15.4)$ & 278 (15.5) & $24(16.3)$ & \\
\hline \multicolumn{5}{|c|}{ Family monthly income (CYN) } \\
\hline$<3000 ¥$ & $394(19.3)$ & $344(19.2)$ & $32(21.8)$ & \multirow{4}{*}{0.683} \\
\hline $3000-5999 ¥$ & $819(40.1)$ & $718(40.0)$ & $62(42.2)$ & \\
\hline $6000-11999 ¥$ & $626(30.7)$ & $555(30.9)$ & $41(27.9)$ & \\
\hline$\geqq 12000 ¥$ & $201(9.9)$ & $179(10.0)$ & $12(8.2)$ & \\
\hline \multicolumn{5}{|l|}{ Monthly expense (CYN) } \\
\hline$<500 ¥$ & $66(3.2)$ & $53(3.0)$ & $8(5.4)$ & \multirow{4}{*}{0.412} \\
\hline $500-999 ¥$ & $759(37.2)$ & $670(37.3)$ & $52(35.4)$ & \\
\hline $1000-1499 ¥$ & $918(45.0)$ & $812(45.2)$ & $65(44.2)$ & \\
\hline$\geqq 1500 ¥$ & 297 (14.6) & $261(14.5)$ & $22(15.0)$ & \\
\hline \multicolumn{4}{|l|}{ Grade } & \multirow{2}{*}{0.008} \\
\hline Grade 1 & $435(21.3)$ & $398(22.2)$ & $20(13.6)$ & \\
\hline
\end{tabular}




\begin{tabular}{|c|c|c|c|c|}
\hline & & & & \\
\hline Grade 2 & $673(33)$ & $572(31.8)$ & $61(41.5)$ & \\
\hline Grade 3 & $484(23.7)$ & $436(24.3)$ & $30(20.4)$ & \\
\hline Grade 4 & $306(15)$ & $267(14.9)$ & $19(12.9)$ & \\
\hline Grade 5 & $142(7.0)$ & $123(6.8)$ & $17(11.6)$ & \\
\hline Major & & & & \\
\hline Clinical medicine & $803(39.4)$ & $729(40.6)$ & $58(39.5)$ & 0080 \\
\hline Nursing & $989(48.5)$ & $845(47.0)$ & $79(53.7)$ & 0.009 \\
\hline Others & $248(12.2)$ & $222(12.4)$ & $10(6.8)$ & \\
\hline Time of concern about COVID-19 (min & & & & \\
\hline$<5$ & $341(16.7)$ & $290(16.1)$ & $31(21.1)$ & \\
\hline $5-9$ & $533(26.1)$ & $479(26.7)$ & $28(19.0)$ & 0.082 \\
\hline $10-29$ & $761(37.3)$ & $672(37.4)$ & $52(35.4)$ & \\
\hline$\geqq 30$ & 405 (19.9) & $355(19.8)$ & $36(24.5)$ & \\
\hline Regard healthcare as dangerous job & & & & \\
\hline No & $881(43.2)$ & $797(44.4)$ & $50(34.0)$ & 0.019 \\
\hline Yes & $1159(56.8)$ & $999(55.6)$ & $97(66.0)$ & \\
\hline Have relatives with medical background & & & & \\
\hline No & $1594(78.1)$ & $1409(78.5)$ & $107(72.8)$ & 0.136 \\
\hline Yes & $446(21.9)$ & $387(21.5)$ & $40(27.2)$ & \\
\hline Parents' attitude towards learning medic & & & & \\
\hline Support & $1410(69.1)$ & $1270(70.7)$ & $95(64.6)$ & $\begin{array}{lll}0107 \\
\end{array}$ \\
\hline Neutral & $557(27.3)$ & $466(25.9)$ & $44(29.9)$ & 0.191 \\
\hline Against & $73(3.6)$ & $60(3.3)$ & $8(5.4)$ & \\
\hline Level of impact brought by COVID-19 & & & & 0006 \\
\hline mean(SD) & $3.5(1.6)$ & $3.5(1.6)$ & $3.8(1.8)$ & 0.000 \\
\hline
\end{tabular}


aincluding 97 missing values;

Abbreviations: CYN, currency in circulation in China.

Table 2 Odd ratios $(95 \% \mathrm{CI})$ of change of career intention for socio-demographic characteristics in logistic regression models.

\begin{tabular}{|c|c|c|c|}
\hline Variable & Adjusted OR $(95 \% \mathrm{CI})$ & $P($ Wald's test $)$ & $P$ (LR-test) \\
\hline Age (year) & $1.07(0.91,1.27)$ & 0.397 & 0.405 \\
\hline \multicolumn{4}{|l|}{ Sex } \\
\hline Male & Reference & & 0.137 \\
\hline Female & $0.72(0.47,1.11)$ & 0.133 & \\
\hline \multicolumn{4}{|l|}{ Residency } \\
\hline Hubei rural & Reference & & \\
\hline Hubei urban & $0.82(0.52,1.31)$ & 0.414 & 0.427 \\
\hline Rural other than Hubei & $1.04(0.63,1.72)$ & 0.877 & \\
\hline Urban other than Hubei & $0.6(0.3,1.17)$ & 0.135 & \\
\hline \multicolumn{4}{|l|}{ Educational level of parents } \\
\hline Middle school or below & Reference & & \\
\hline High school & $1.12(0.72,1.73)$ & 0.616 & 0.78 \\
\hline College & $0.9923(0.4917,2.0028)$ & 0.983 & \\
\hline University or above & $1.32(0.75,2.35)$ & 0.337 & \\
\hline \multicolumn{4}{|c|}{ Family monthly income(CYN) } \\
\hline$\leqq 3000 ¥$ & Reference & & \\
\hline $3000-5999 ¥$ & $1.02(0.63,1.64)$ & 0.937 & 0.55 \\
\hline $6000-11999 ¥$ & $0.79(0.45,1.39)$ & 0.416 & \\
\hline$\geqq 12000 ¥$ & $0.64(0.28,1.47)$ & 0.294 & \\
\hline
\end{tabular}




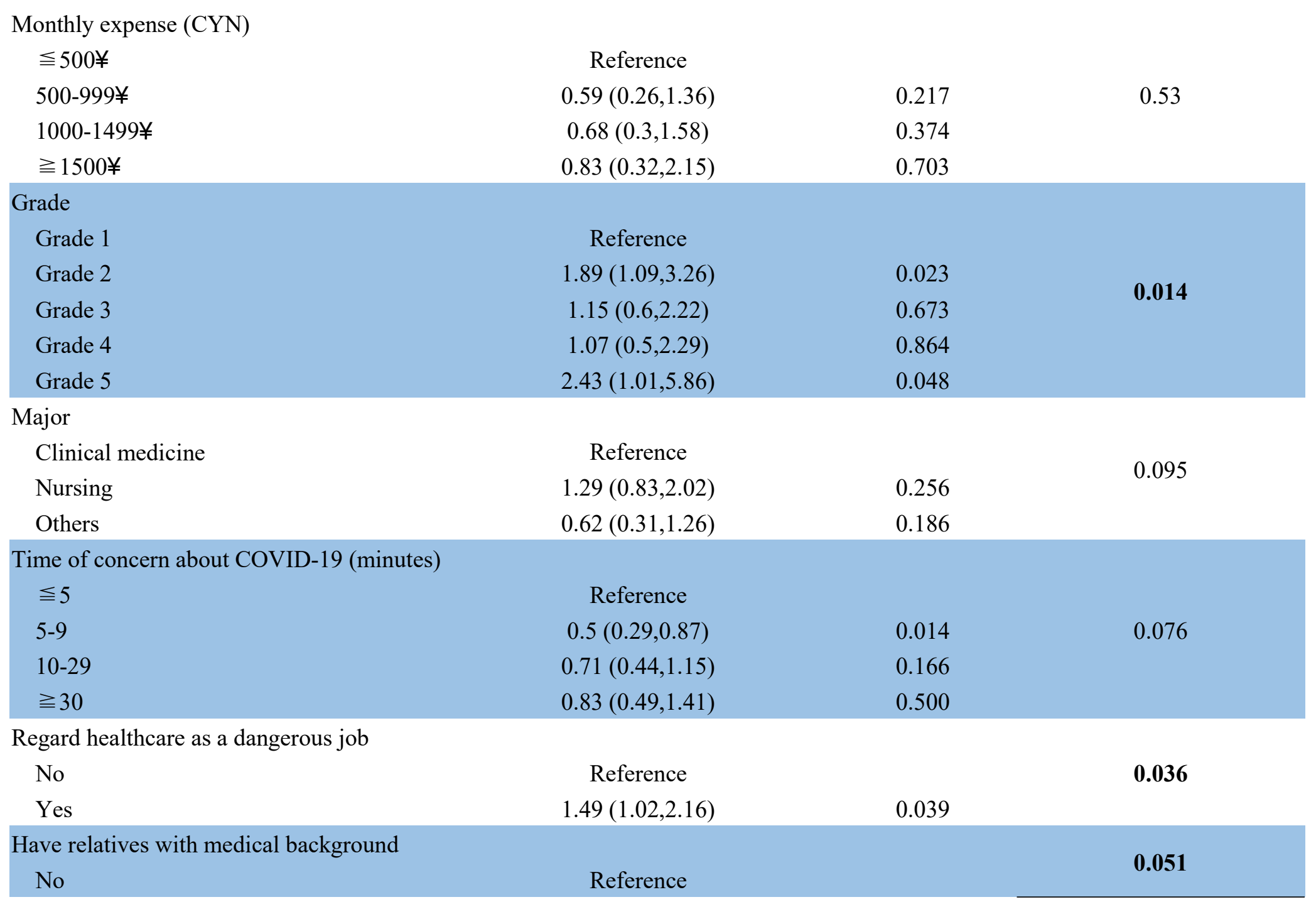




$\begin{array}{lccc}\text { Yes } & 1.53(1.01,2.32) & \mathbf{0 . 0 4 7} & \\ \text { Parents' attitude towards learning medical } & & & \\ \text { Support } & \text { Reference } & 0.232 \\ \text { Neutral } & 1.18(0.8,1.75) & 0.402 & 0.089 \\ \text { Against } & 1.99(0.9,4.41) & 0.065 & 0.067 \\ \text { Level of impact brought by COVID-19 } & 1.11(0.99,1.23) & \end{array}$

Table 3 Multiple logistic regression analysis of factors associated with career preference,career perspective and workplace preference.

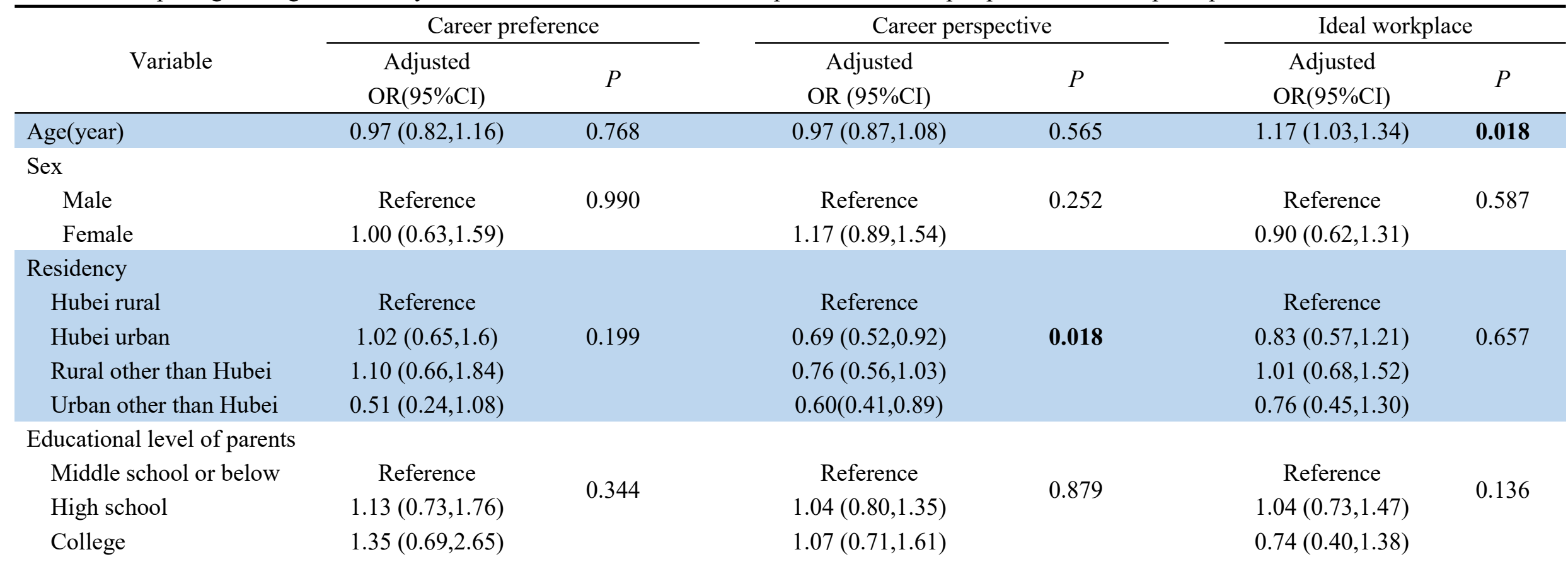




\begin{tabular}{|c|c|c|c|c|c|c|}
\hline University or above & $1.68(0.96,2.92)$ & & $0.91(0.64,1.31)$ & & $1.49(0.96,2.33)$ & \\
\hline \multicolumn{7}{|c|}{ Family monthly income(CYN) } \\
\hline $3000-5999 ¥$ & $0.71(0.45,1.14)$ & \multirow[t]{2}{*}{0.187} & $0.88(0.66,1.18)$ & \multirow[t]{2}{*}{0.448} & $0.94(0.64,1.38)$ & \multirow[t]{2}{*}{0.329} \\
\hline$\geqq 12000 ¥$ & $0.60(0.26,1.36)$ & & $1.06(0.65,1.72)$ & & $0.58(0.29,1.15)$ & \\
\hline \multicolumn{6}{|l|}{ Monthly expense(CYN) } & \multirow{3}{*}{0.076} \\
\hline$\leqq 500 ¥$ & Reference & \multirow{2}{*}{0.015} & Reference & \multirow{2}{*}{0.282} & Reference & \\
\hline$\geqq 1500 ¥$ & $0.44(0.17,1.14)$ & & $1.36(0.66,2.82)$ & & $0.88(0.41,1.90)$ & \\
\hline \multicolumn{6}{|l|}{ Grade } & \multirow{4}{*}{0.200} \\
\hline Grade 1 & Reference & \multirow{3}{*}{0.024} & Reference & \multirow{3}{*}{0.605} & Reference & \\
\hline Grade 2 & $2.21(1.29,3.78)$ & & $1.16(0.86,1.58)$ & & $1.54(1.00,2.37)$ & \\
\hline Grade 3 & $1.30(0.67,2.55)$ & & $1.09(0.75,1.57)$ & & $1.30(0.79,2.13)$ & \\
\hline Nursing & $1.41(0.90,2.21)$ & \multirow{2}{*}{0.021} & $1.32(1.01,1.73)$ & \multirow{2}{*}{0.108} & $2.07(1.42,3.03)$ & \multirow{2}{*}{$<0.001$} \\
\hline Others & $0.53(0.24,1.16)$ & & $1.05(0.73,1.51)$ & & $1.04(0.61,1.77)$ & \\
\hline \multicolumn{7}{|c|}{ Time of concern about COVID-19(minutes) } \\
\hline$\leqq 5$ & Reference & \multirow{4}{*}{0.216} & Reference & \multirow{4}{*}{0.945} & Reference & \multirow{4}{*}{0.919} \\
\hline $5-9$ & $0.64(0.38,1.08)$ & & $1.00(0.72,1.40)$ & & $0.85(0.55,1.32)$ & \\
\hline $10-29$ & $0.59(0.36,0.97)$ & & $1.05(0.77,1.43)$ & & $0.91(0.60,1.37)$ & \\
\hline$\geqq 30$ & $0.72(0.42,1.23)$ & & $0.96(0.67,1.36)$ & & $0.92(0.58,1.46)$ & \\
\hline
\end{tabular}


Have relatives with medical background

No

Reference

0.390

Reference

0.021

Reference

0.811

Yes

$1.21(0.78,1.88)$

$1.37(1.05,1.78)$

$1.05(0.73,1.50)$

Parents' attitude toward learning medical

Support

Neutral

Reference

$1.64(1.13,2.38)$

$0.82(0.28,2.37)$

Against $1.17(1.06,1.30)$

0.031

Reference

$1.06(0.84,1.35)$

0.588

Reference

$1.32(0.97,1.79)$

$0.99(0.46,2.14)$

$1.08(1.01,1.15)$

0.016

$1.11(1.02,1.21)$

0.200

$\mathbf{0 . 0 0 3}$

Abbreviations: CYN, currency in circulation in China.

Figure1 Stratified analysis of factors associated with career choice by UM students' major. 


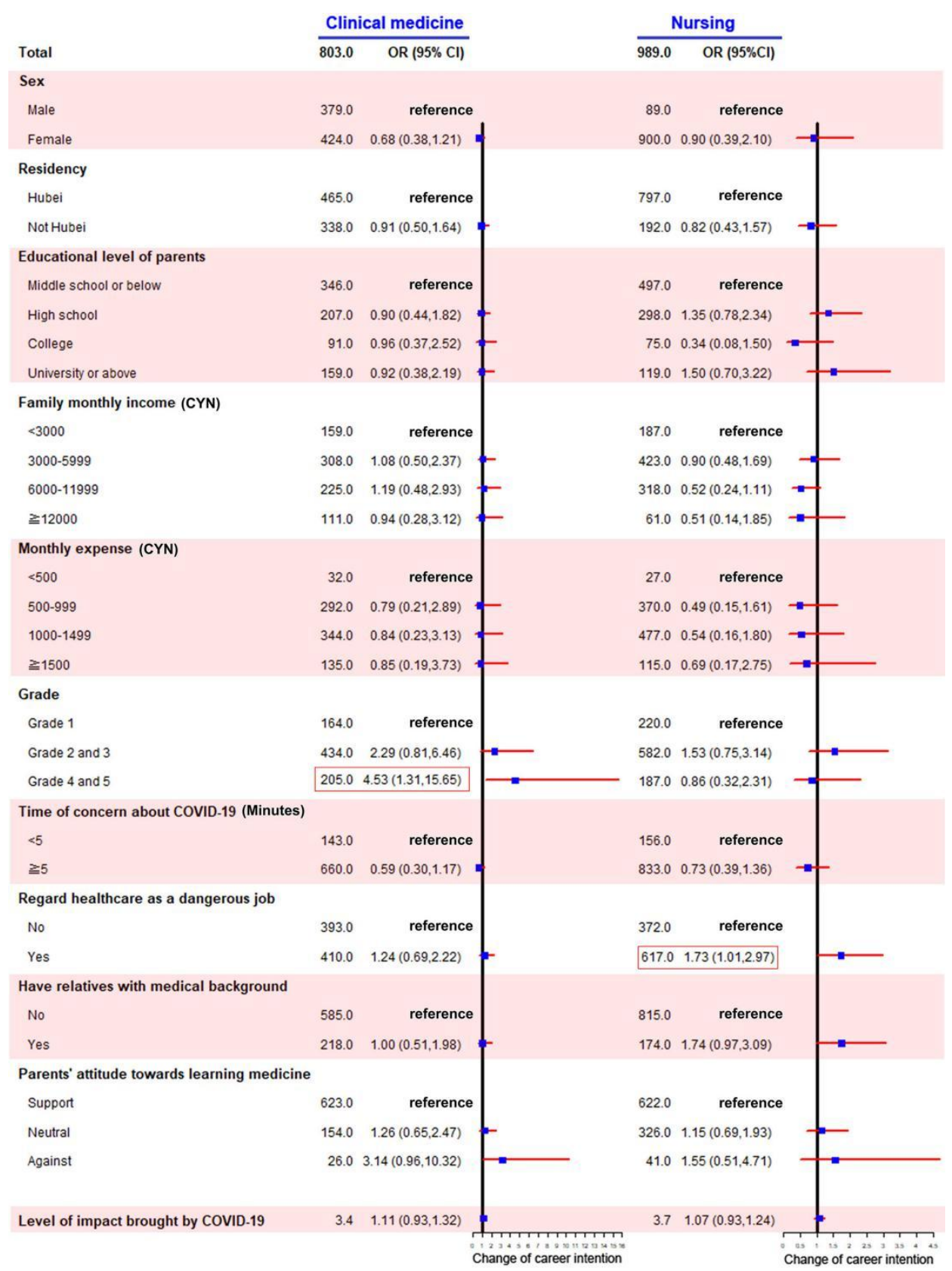

